Original Research Paper

\title{
Proposal of a Standardized Electronic Health Record for Kingdom of Saudi Arabia
}

\author{
Hussain Mohammad Abu-Dalbouh, Memonah Al-Matrouk, Norah Al-Zwaid and Arwa Al-Handi \\ Department of Computer Sciences, \\ College of Sciences and Arts in Unaizah, Qassim University, Al-Qassim, Kingdom of Saudi Arabia
}

\author{
Article history \\ Received: 23-02-2019 \\ Revised: 20-04-2019 \\ Accepted: 30-04-2019 \\ Corresponding Author: \\ Hussain Mohammad Abu- \\ Dalbouh \\ Department of Computer \\ Sciences, College of Sciences \\ and Arts at Unaizah, Qassim \\ university, Unaizah, Al- \\ Qassim, Saudi Arabia \\ Email: hussainmdalbouh@yahoo.com \\ Memonah Al-Matrouk \\ Department of Computer \\ Sciences, College of Sciences \\ and Arts at Unaizah, Qassim \\ university, Unaizah, Al- \\ Qassim, Saudi Arabia \\ Email: memonah777@gmail.com
}

\begin{abstract}
Electronic Health Records are electronic versions of patients' healthcare records. An electronic health record gathers, creates and stores the health record electronically. The electronic health record has been slow to be adopted by healthcare providers. The proposed electronic health record will improve clinical documentation, quality, healthcare utilization tracking, billing and coding and make health records portable. The core components of an electronic health record include administrative functions, computerized physician order entry, lab systems, radiology systems, pharmacy systems and clinical documentation. The proposed electronic copy of the patient's health record includes all of data and important information of the patient and the patients' history and the history of the family in cooperation with the doctor. Examples of the information available in the proposed electronic health record: Patient personal information, medications, laboratory tests results, X-rays, vital symptoms and other results. It is a website that aims to serve the health community through a standardized electronic health records for all hospitals and clinics in the Saudi Arabia Kingdom. A doctor can, through this electronic records, input and read a health record and know about health history of the patient. Consequently, it will be easy for a doctor to diagnose and treat a patient in a correct way. The proposed system is reduced medical errors through exchanging experiences among doctors and knowing drugs that conflicted with similar previous health conditions. The experimental results conclude that the working environment would be improved the performance of health professionals, reduce operation/administrative costs and enhance patient safety.
\end{abstract}

Keywords: Laboratory, Lab, System, Patient, Technology, Hospital, Clinical, Website

\section{Introduction}

In recent years with the numerous advances in data innovation in the technology, especially in medicinal services, various diverse types of Electronic Health Records (EHR) have been examined, created and executed. A few organizations/nations are at present arranging the presentation of an across the nation electronic health record while others have really actualized some type of EHR. In any case, the sort and degree of electronic health records shift and what one nation calls an EHR may not be equivalent to that created in another nation. In spite of the fact that work has been embraced by organizations/nations on some type of a modernized patient human services data framework, up until now relatively few doctor's facilities have effectively presented an electronic wellbeing record with clinical information passage at the purpose of consideration (Abu-Dalbouh, 2019; Lohr, 2009).

In spite of the fact that enthusiasm for mechanizing the health record is commonly high in both developed and developing countries unfortunately, now and again, the presentation of an EHR framework appears to be overpowering and practically distant to numerous human services suppliers and executives just as medicinal record/health data supervisors. For what reason is this so? The impediments may not be accessible innovation but rather specialized help and the expense of changing 
to an electronic framework combined with lacking electronic record financing. In many creating nations costs, electronic record accessible innovation, absence of specialized mastery and computer abilities of staff and absence of information handling offices are in certainty serious issues which would should be tended to before usage is conceivable (Abu-Dalbouh et al, 2017; Abu-Dalbouh, 2014a; Abu-Dalbouh and Almueit, 2013; Milliard, 2012; Wiedemann, 2012). The paper is organized as follows: Section 2 provides the background and overview of the health care in Saudi Arabia. Section 3 presents the definition of the electronic health record. Section 4 proposed electronic health record system. Section 5 discusses the results of this study. A conclusion is presented in the last section.

\section{Health Care System in Saudi Arabia: An Overview}

Since the cutting edge territory of Saudi Arabia was first established by King Abdul Aziz Bin Abdul Rahman Al Saud, general health and ailment control were among the administration's top needs. The production of the Kingdom's human services framework corresponded with King Abdul Aziz's takeover of Al Hijaz and his assignment of Mecca as the primary Saudi capital. The direction of the establishing King of Saudi Arabia enabled the new government to defeat the numerous obstacles and difficulties in the beginning of the country, in spite of an absence of local assets and aptitude. HRH's system was to reinforce the Kingdom's participation with worldwide associations and to team up with exceedingly qualified remote specialists. In spite of keeping pace with the most recent global human services improvements, the King moreover centered around structure a solid foundation for a far reaching health part that would serve all areas of the Kingdom.

In 1343H/1925, King Abdul Aziz set up the Public Health Department in Makkah Al-Mukaramah. In 1344H 1925 , Public Health and Ambulance was set up to address the issues of the Kingdom's health and ecological areas. The PHA manufactured clinics and health focuses over the Kingdom and issued and authorized guidelines to ensure sufficient principles for the rehearsing of medicine and pharmacology.

The expanding extent of social insurance administrations required in the Kingdom amid that period, including care for Hajj and Umrah entertainers, made the requirement for the development of a Public Health Council. This gathering was the most elevated amount supervisory board in the Kingdom and directed all parts of medicinal services, including all clinics and social insurance focuses across the nation. The board's principle objectives incorporated the advancement of a gifted human services workforce, in addition to the control of the illnesses and pandemics which were common amid that time.
According to (Ministry of Health, 2014 site) it was important to make a vast scaled, specific association to do the Kingdom's health undertakings. Illustrious declaration Num. 8697\11\5 was issued on 26-8-1370H\1915 and built up the Ministry of Health. With the foundation of the Ministry, King Abdul Aziz's initial vision of present day national social insurance administrations was well on its way towards turning into a reality.

Health information is a special kind of personal information. From one perspective, it is amazingly touchy, requiring the most grounded protection and security assurances to avert unapproved use and exposure. Then again, it ought to be promptly accessible to a wide scope of medicinal services suppliers for the reasons for conveying human services to the person. This twofold nature of individual health information presents one of a kind difficulties for doctors making the progress from paper-based records to electronic frameworks of individual health information.

It offer many advantages to experts and patients. As a rule, paper-based records might be inadequate, spread over a scope of medicinal services supplier areas and hard to find and peruse. Conversely, a common electronic record of individual health information might be promptly gotten to by the majority of the people's social insurance suppliers, paying little mind to where they are found. It is additionally bound to contain total and cutting-edge individual health information around a person. An electronic record requires less space and less authoritative assets to keep up. It underpins improved clinical basic leadership prompting progressively compelling determination and treatment, more noteworthy patient health, expanded productivity and improved access to administrations.

With electronic records of personal health information, there is the potential for mechanizing, organizing and streamlining clinical work process and incorporating a wide scope of discrete medicinal services administrations including choice help, tolerant checking, electronic endorsing, electronic referrals, radiology, research facility requesting and results show. Electronic health information frameworks can likewise give an information trail that can be promptly utilized for the reasons for therapeutic review, health research, quality affirmation, epidemiological checking and illness reconnaissance (Abu-Dalbouh et al., 2015; AbuDalbouh, 2013; Cavoukian and Rossos, 2009).

\section{Department of Saudi Diseases Registries}

In light of the regal bureau of services goals no. (11) Dated 12/1/1434H (2012), the Saudi Health Registries was set up as a component of the national focal point of health information. The primary point 
of Saudi sicknesses vaults division is to be the approved body for supervision, guideline and to help improvement of national related occasions/illnesses libraries in the Kingdom of Saudi Arabia. The Saudi maladies vaults division has duties over the current libraries and setting benchmarks for making of new libraries. The by-law of maladies libraries was endorsed by Saudi wellbeing gathering goals NO. (66/7) dated 13/9/1434H (2013).

The health registry is a progressing, orderly and comprehensive information source which outlines the predominance of medical issues in the network just as decides the etiological components that can be utilized for arranging and executing of preventive systems. Health Registries are arranged to three classes: (1) Diseases registries: are characterized by patients having a similar finding. (2) Medical devices registries: incorporate patients who have been presented to same restorative gadgets. (3) Health services registries: Comprise of patients who have a typical method, clinical experience, or hospitalization. The fundamental objective of Saudi sicknesses libraries division is to be an important wellspring of national epidemiological data for approach creators and wellbeing administrations' organizers to survey, assess and improve the nature of wellbeing administrations in the KSA.

The Saudi Cancer Registry is the main national vault in KSA and it fill in as model for setting up other national libraries. It was built up in $(1412 \mathrm{H}) 1992$ by a goals of Health Minister, the fundamental office of Saudi Cancer Registry was at the King Faisal Specialist Hospital and Research Center in Riyadh. It started recording malignant growth cases in the Kingdom since January 1994 (1414 H). At that point, it was moved under the specialist of the Saudi Health Council in (1435 $\mathrm{H})$. The Saudi Cancer Registry gathers malignant growth information from all clinics in KSA through 5 local workplaces where as information examination and intermittently announcing occur at the primary office. The Saudi health registries utilizing progressed electronic frameworks and team up with national and universal associations to give preparing projects to the staff to guarantee high caliber of information and apply perceived measures for security and secrecy of information (Saudi Health Council site).

This study, it has been decided to create an electronic site on computer to serve the individuals of the society whether they are doctors or patients. First, we have to appoint the page user. If he/she is a patient, he/she selects the choice "my file" and enter his civil register and password. However, if he is a doctor, he clicks the choice "doctor" and enter his/her civil register and password, Then choose patient's one he/she wants to access to his page which will contain the patient's information, his healthy condition, copies of labs, x-rays, diagnose and treatment described. Doctor can write and add any new information. There on.

\section{Definition of an Electronic Health Record}

Electronic Health Records (EHR's) are as well generally known as Electronic Medical Records (EMR's) and the two terms are used conversely (Torrey, 2011). The EHR is an electronic rendition of a patient's health record that was verifiably made, utilized and put away in a paper graph. A patient EHR is made, overseen and held by the organization of health care systems (Roman, 2009). Only health care provider who are associated with a patient's consideration can access and utilize an electronic health record (Roman, 2009). A Personal Health Record (PHR) is a health record that a patient controls and can change (Roman, 2009). EHR's are secured under a government law called Health Insurance Portability and Accountability Act (HIPAA); PHR's are not secured under HIPAA (Roman, 2011).

According to National Institute of Health report (2006) the definition of an EHR:

The EHR is a longitudinal electronic record of patient health data produced by at least one experiences in any consideration conveyance setting. Incorporated into this data are persistent socioeconomics, advance notes, issues, drugs, indispensable signs, past restorative history, inoculations, research facility information and radiology reports. The EHR robotizes and streamlines the clinician's work process. The EHR can create a total record of a clinical patient experience, just as supporting other consideration related exercises legitimately or by implication by means of interface, including proof based choice help, quality administration and result's revealing. (p. 1).

This EHR is made and utilized by doctors in their centers and by emergency clinics and other human services offices (History of the Electronic Medical Record System (n.d.)).

\section{Proposed Electronic Health Record Website}

It is a website that aims to serve the Saudi health community through replacing paper-based health records with standardized and fixed electronic records for all hospitals and clinics in the Kingdom. A doctor can, through theses electronic records, input and read a health record and know about health history of his/her patient. Consequently, it will be easy for a doctor to diagnose and treat a patient in a correct way. This website may contribute to reduce medical errors through exchanging experiences among doctors and knowing drugs that conflicted with similar previous health conditions. The proposed electronic health record serves a patient since when he/she wants to 
move to another hospital for treatment, very easy to access to his/her health record on the proposed electronic health.

The proposed system requires determining the access type. If the user is a patient and he/she wants to read about his/her file, the patient should choose my file option. If the user is a doctor, then should choose the doctor's option. When a patient chooses my file option and wants to login to his/her file, the patient has to input his/her national identity card number and a password. The patient is only allowed to browse his/her file, but the patient is not allowed to edit or add any data. Yet, the patient is allowed to edit his/her personal information. The proposed electronic health record will improve clinical documentation, quality, healthcare utilization tracking, billing and coding and make health records portable. The end-users of the proposed system are Doctor and Patient.
The functionality of a system as Doctor Actor: The doctor should press to login the system as a Doctor as shwoun in Fig. 2, then the Doctor should input his/her national identity card number and a password. Then, the doctor need to search for the patient by a searching list in the file as shown in Fig. 3. The patient profile example as shown in Figs. 4 and 13. The functions: View a list of patients, View patient's records, View or update diagnosis as shown in Fig. 5, View and update treatment as shown in Fig. 6, View or update chronic disease as shown in Fig. 7, View or update laboratory, View or update detection as shown in Figures 8, 9 and 10, Contact with patient as shown in Fig. 11, Write note to other doctors as shown in Fig. 12. Figure 1 shows the functionality of doctor actor and then the following snapshots explain the (EHR) system.

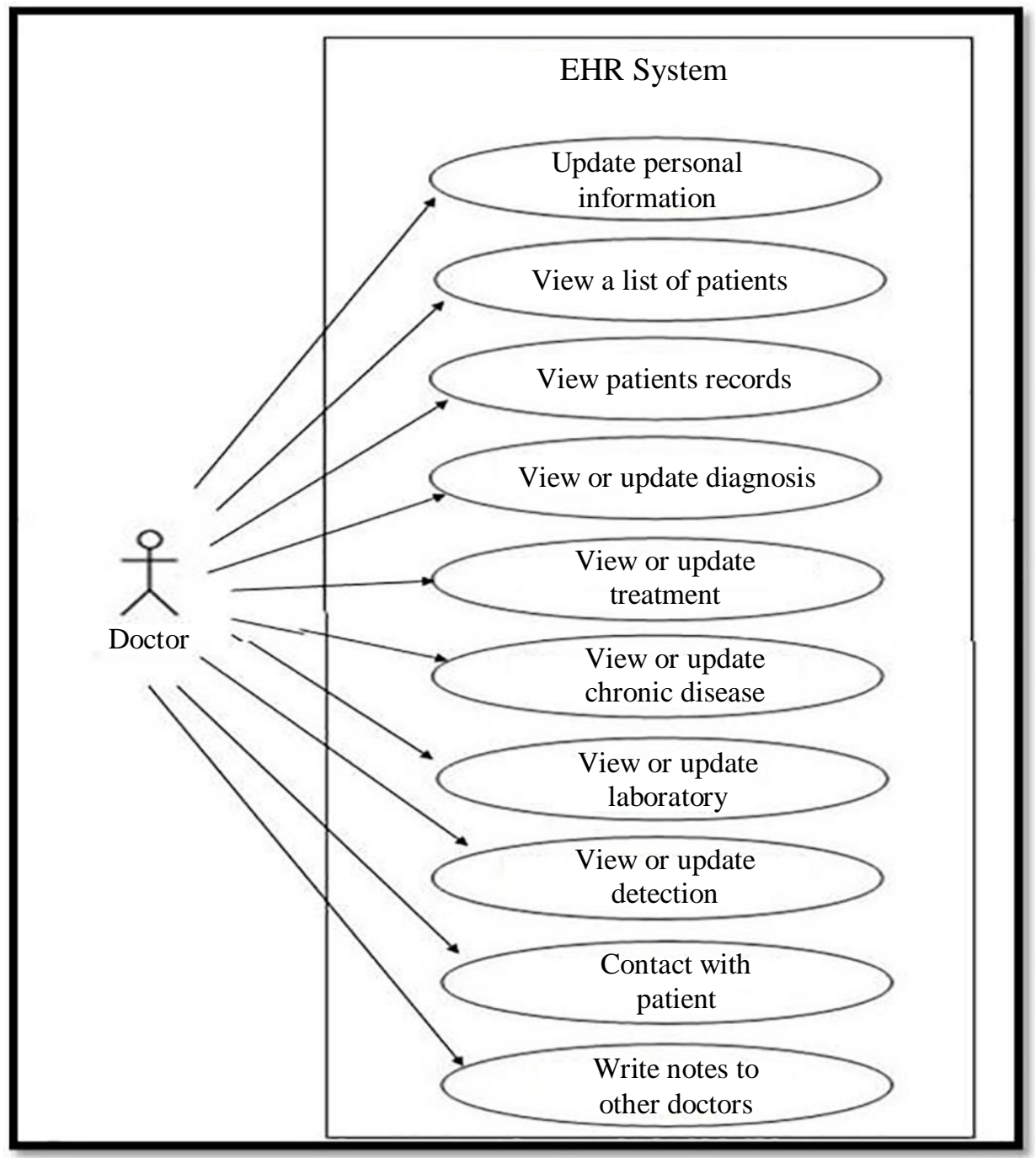

Fig. 1: The functionality of doctor actor 


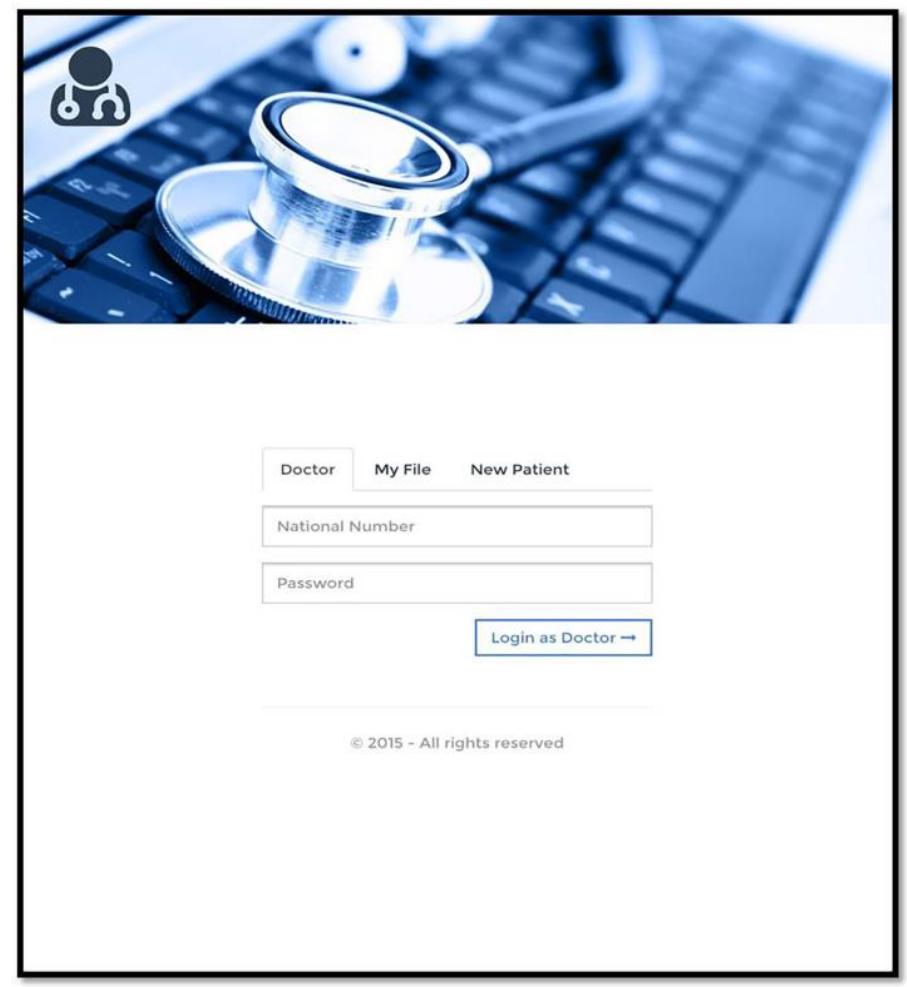

Fig. 2: Screen to login in EHR

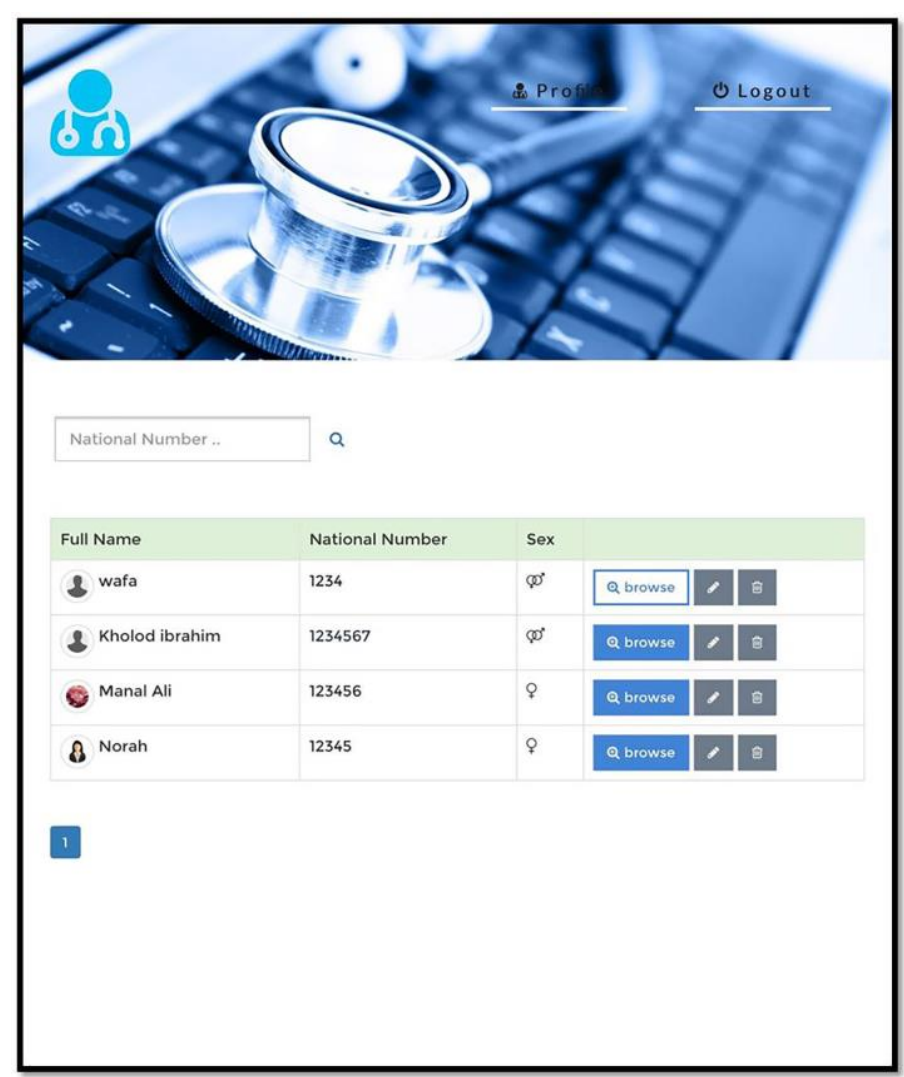

Fig. 3: Login in EHR by doctor and shown list of patient 


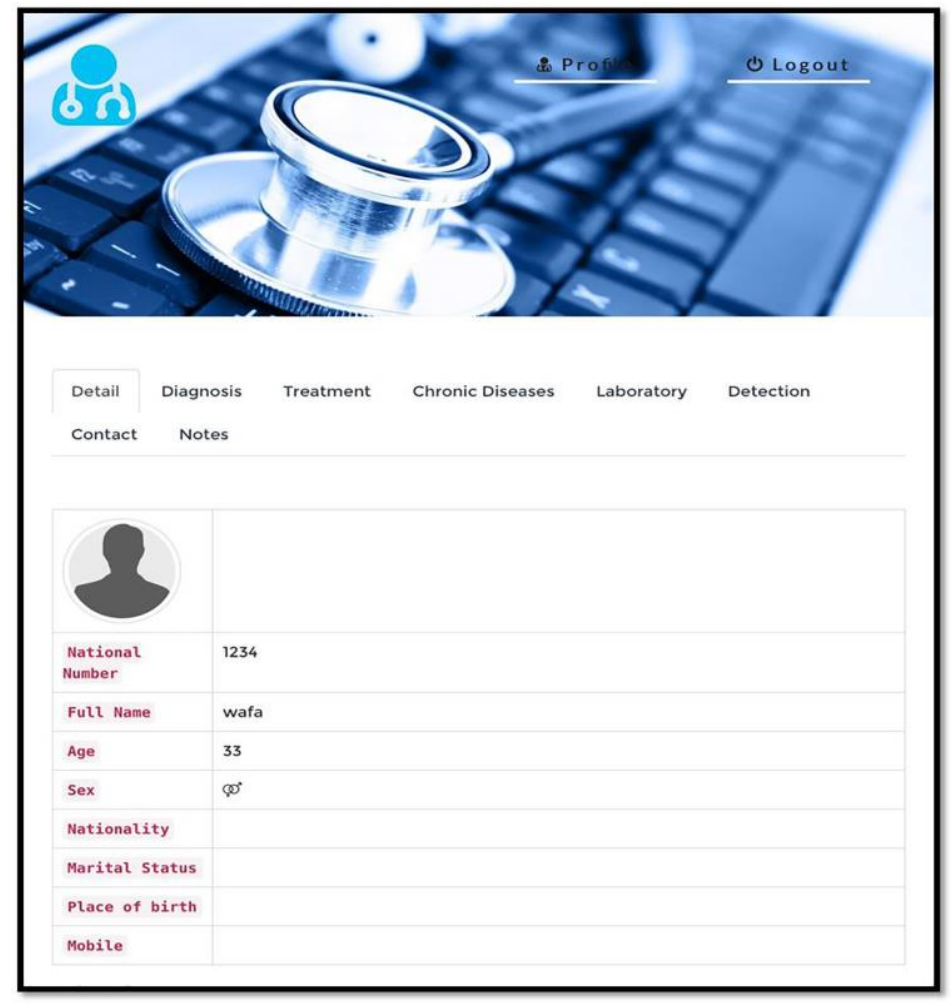

Fig. 4: Patient profile example

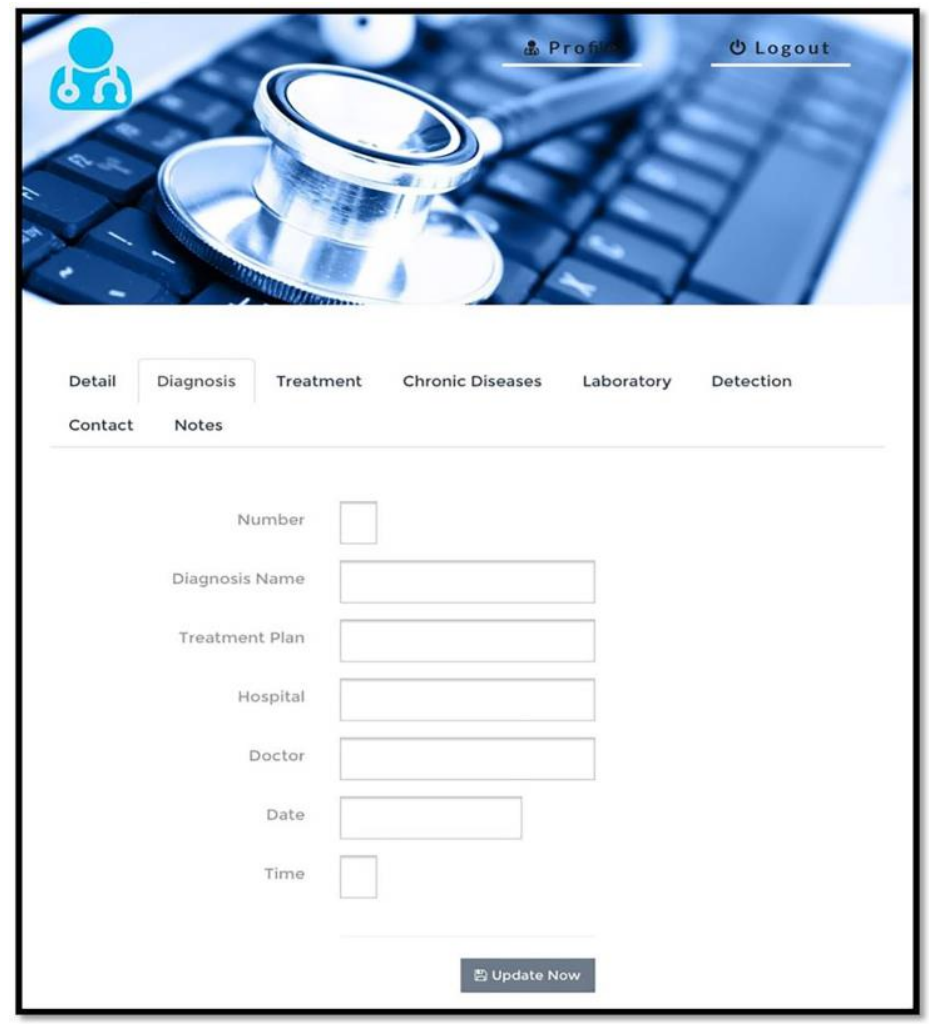

Fig. 5: The Diagnosis page (Diagnosis: The doctor is input a disease status number, the treatment plan that is being followed, diagnosis date of the disease, name of the doctor that examined it and the name of hospital in which the disease has been examined) 


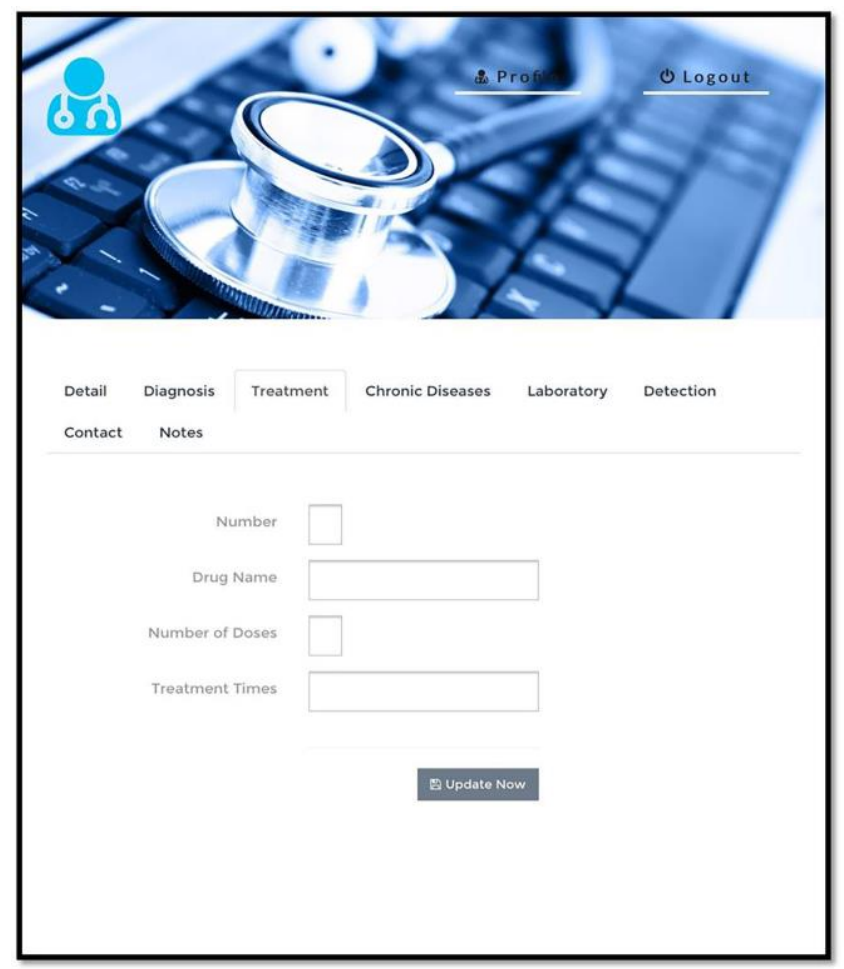

Fig. 6: Treatment page (Treatment: Status number, treatment name, number of daily doses and times in which the treatment should be taken will be input in this page)

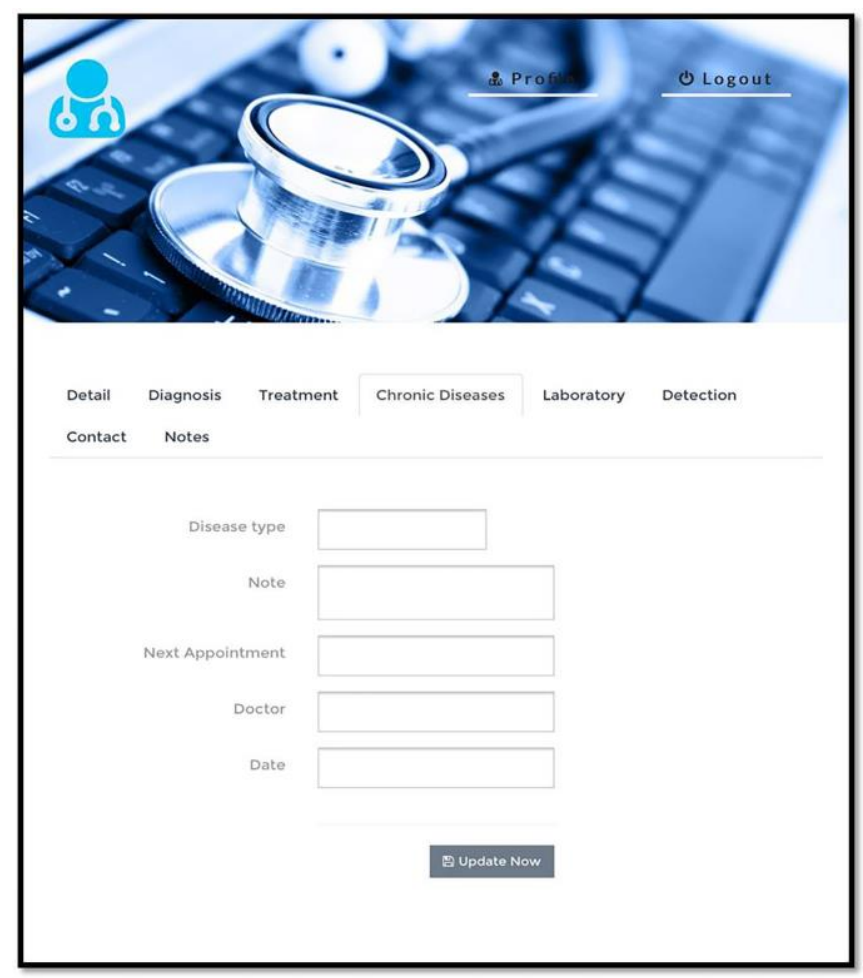

Fig. 7: The Chronic Diseases (Chronic Diseases: In this page, chronic and associated diseases of the patient are going to be identified. Thus, the doctor will be able to know about his patient and what he is suffering from. There is also a follow up for pressure and diabetes and writing notes in this page) 


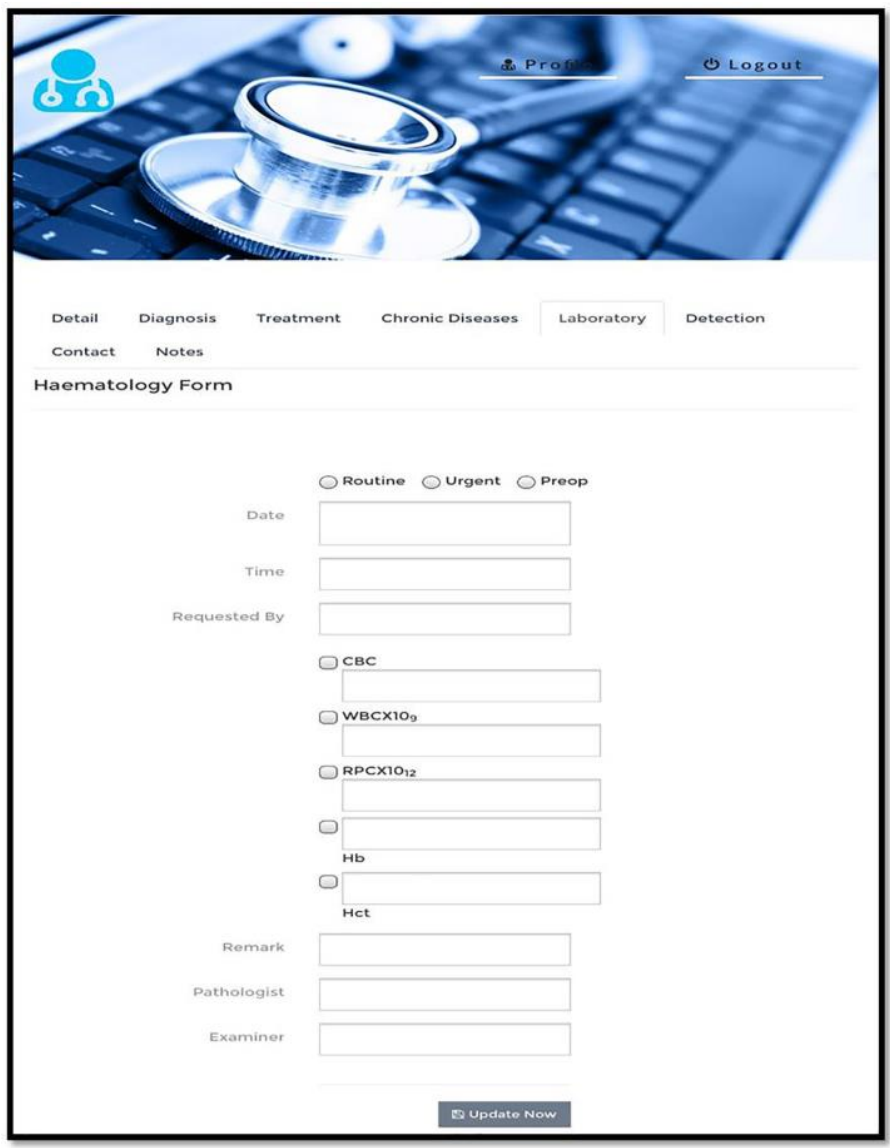

Fig. 8: The Haematology form branch of Laboratory page (Laboratory: This contains laboratory results and is divided into: Hematology form, Microbiology that is divided into two main parts: Urine Sample Analysis form and Stool Sample Analysis form)

Microbiology

Urine Analysis Form
Microbiology

Stool Analysis Form
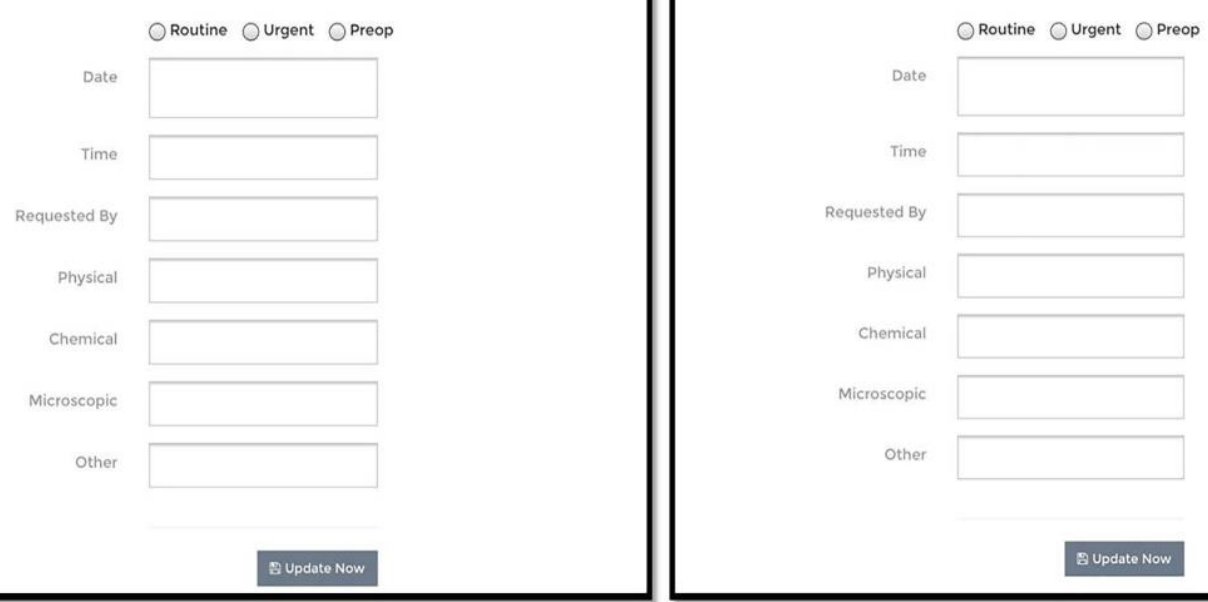

Fig. 9: The urine analysis form and stool analysis 

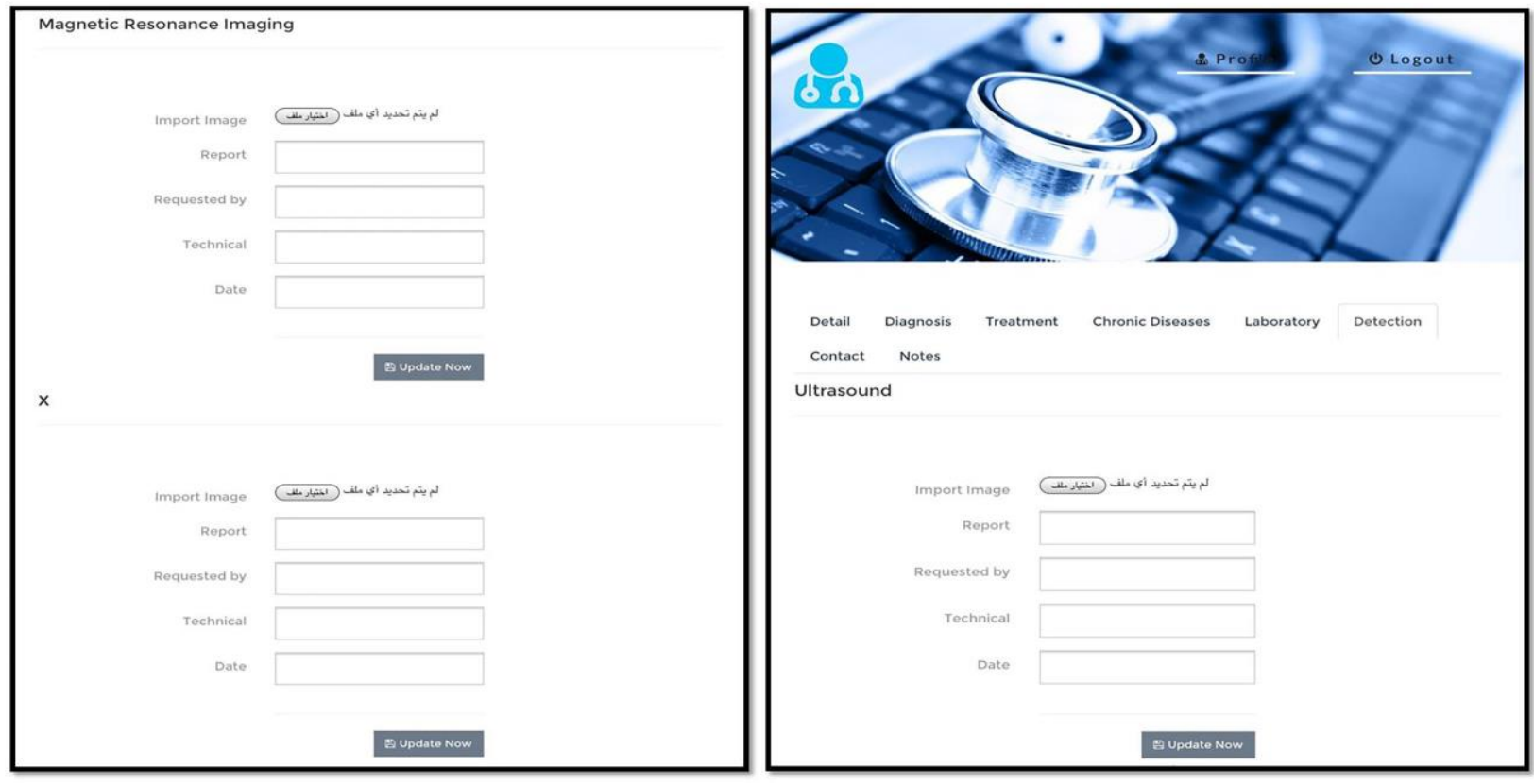

Fig. 10: The magnetic resonance image and X-ray branches of detection page (Detection: It contains three sub-pages each of which has a place to input the copy and write a report about it. Detection divisions: Ultrasound, Magnetic Resonance Imaging and Normal X-Ray)

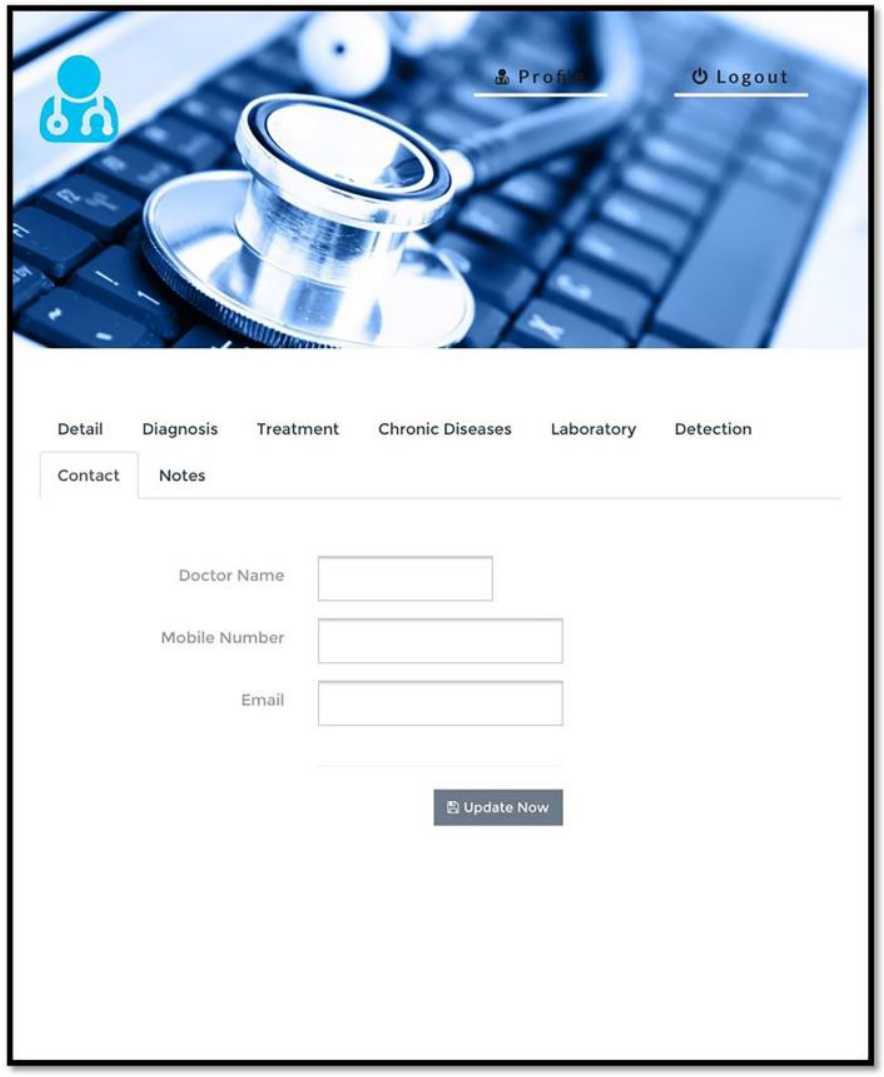

Fig. 11: Contact page (Contact: In this page, doctor's name, phone number and e-mail are input in order to enable the patient to contact with him) 


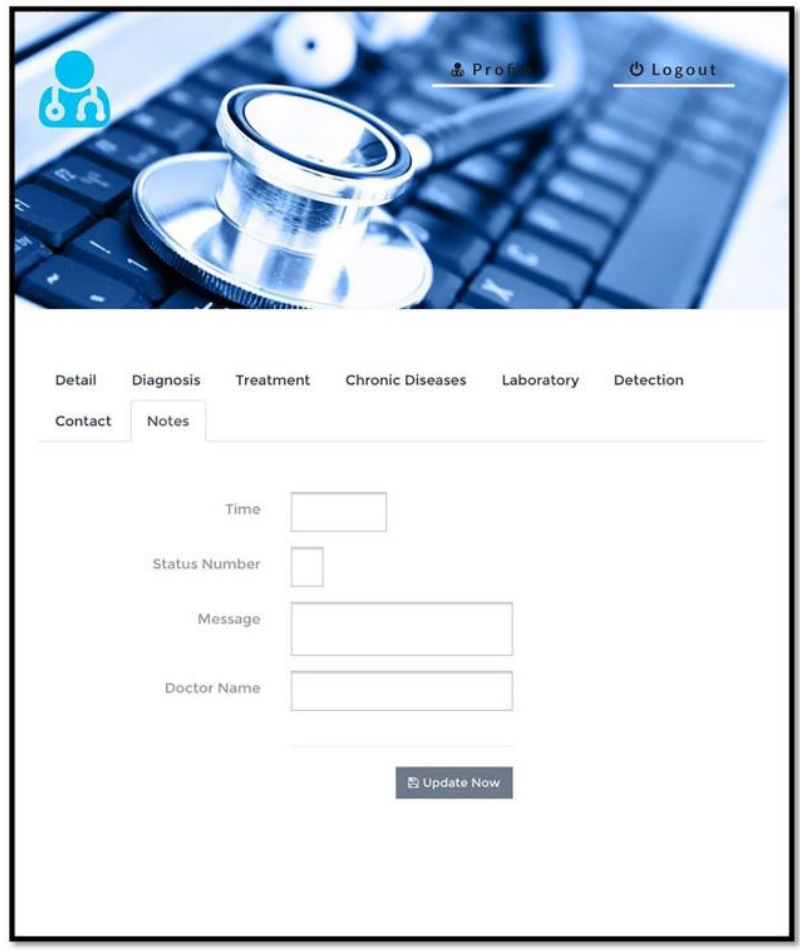

Fig. 12: Notes page (Notes: This page is supposed to appear for doctors only. On this page, the doctor writes a note for another doctor who may treat the patient in the future. In this note, he states the patient's condition, what he is suffering from and the disease complication that may be occurred and the doctor does not want the patient to know about it. The doctor may add some recommendations that are being followed to treat this patient)
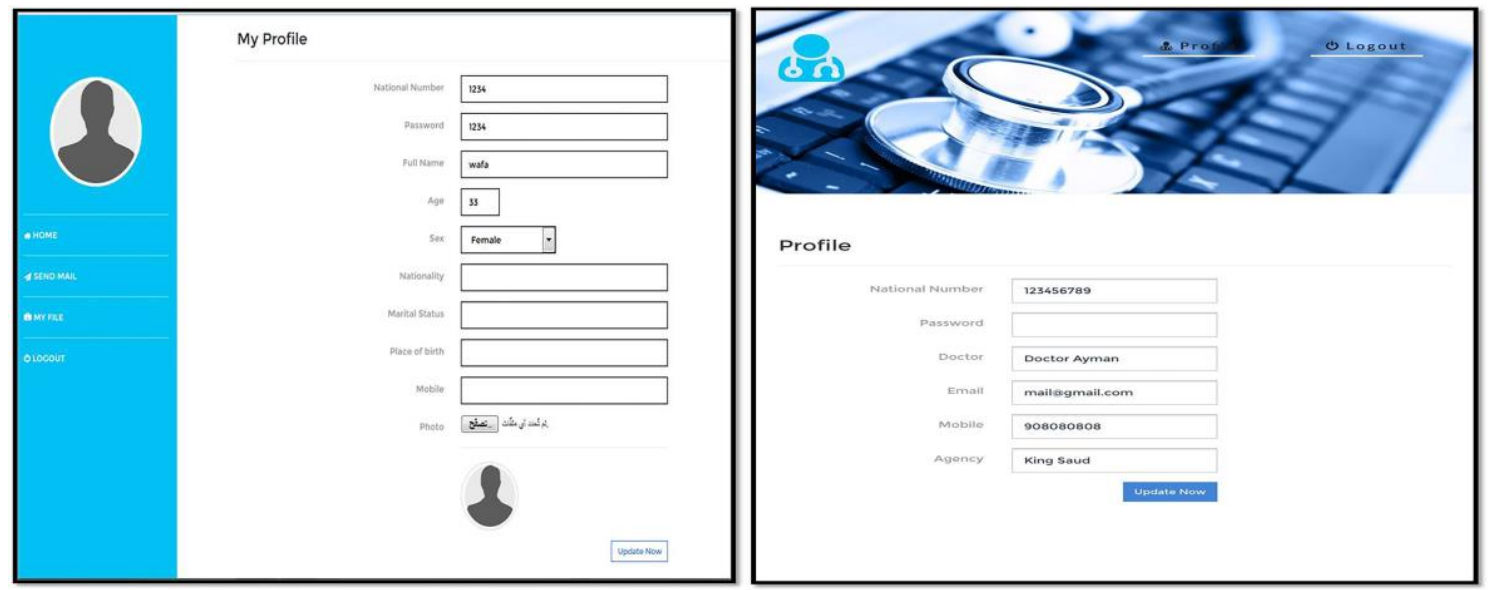

Fig. 13: Doctor and patient profiles

\section{Materials and Methods}

The decision of whether to carry out a qualitative or a quantitative approach lies on the researcher's assumptions (Kanaan, 2009; Abu-Dalbouh, 2013; 2014b; 2016a; 2016b). The present study is based quantitative approach and a questionnaire is utilized for the purpose of meeting the objectives of the study. We decide on for a quantitative as it helps to provide a description of the trends in a population or a description of the relationships among its variables
(Creswell, 2011; Abu-Dalbouh, 2013; Abu-Dalbouh et al., 2017). In addition to this advantage, a quantitative is also inexpensive to be conducted and it is less time consuming as it enables the researcher to acquire both quantitative scale and qualitative data from a large research sample. For this reason, a questionnaire design coupled with quantitative analysis was employed in the present study to examine the variables in the adoption model and to achieve evaluation of using proposed electronic health record system. Moreover, a Likert scale is applied for each set 
of questionnaires. The likert scale is designed to examine how strongly subjects agree or disagree with statements on a five-point scale with the following anchors: (1) Strongly disagree, (2) Disagree, (3) Nature, (4) Agree, (5) Strongly agree (Chomeya, 2010). In this study the proposed methodology was developed in five phases. For every phase has process step(s) and output for better understanding of what the main goal of every phase as presented in methodology section (Abu-Dalbouh, 2013; 2016a; 2016b; 2019).

Perceived of Usefulness: It is defined the degree to which a healthcare professional believes that healthcare industry will be improving by using the proposed electronic health record. The measurement of perceived usefulness comprises of 7 items modified to the context of this study as shown in Table 1.

Perceived Ease of Use: It refers to the degree to which believes that using the proposed electronic health record system in order to improve the quality of treatment in the hospitals. The measurement of perceived ease of use construct contained 5 items and modified to the context of this study as shown in Table 2.

User Satisfaction: It can be experienced in a variety of situations and connected to system. It is a highly personal assessment that is greatly affected by user expectations. The measurement of user satisfaction construct contained 5 items and modified to the context of this study as shown in Table 3 .

Attribute of Usability: It is the area of Human Computer Interaction (HCI) with proposed electronic health record system. It attempts to bridge the gap between human's goals and the system. This is being done by introducing the human issues into the design of interactive mobile electronic health record system and by devising practical techniques to observe human behavior and observe their performance. The measurement of attribute of usability construct contained 5 items and modified to the context of this study as shown in Table 4.

Table 1: Perceived of usefulness items

\begin{tabular}{lll}
\hline Construct & Operational definitions & Measured items \\
\hline Perceived & Perceived usefulness is a feeling & PU1: Proposed Electronic Health Record (EHR) system enhances creativity \\
of Usefulness & that the proposed Electronic & PU2: Proposed Electronic Health Record (EHR) system will be improved \\
& Health Record (EHR) system can & quality of care through greater access to information and history of the patient \\
& access patient charts and medical & PU3: Proposed Electronic Health Record (EHR) system will improve decision- \\
& histories without having to search & making and thinking strategies \\
& files or wait for chart pulls. & PU4: Proposed Electronic Health Record (EHR) system curtails medical errors \\
& Connected electronic health & due to paper-based systems \\
records over secure wireless or & PU5: Proposed Electronic Health Record (EHR) system Helps increase speed of \\
the Internet provide remote access & diagnosis and treatment \\
& to medical & PU6: Proposed Electronic Health Record (EHR) system Improves caregiver \\
& productivity and optimizes workflow efficiency \\
& PU7: Better information and improved communications at the point of care \\
& by using Proposed Electronic Health Record (EHR) system \\
\hline
\end{tabular}

Table 2: Perceived Ease of Use Items

\begin{tabular}{lll}
\hline Construct & Operational definitions & Measured items \\
\hline Perceived & Perceived ease of use refers & EU1: Learning to operate Proposed Electronic Health Record \\
to a level of easiness that & (EHR) system would be ease for me \\
doctors and nurses feel when & EU2: I would find it easy get Proposed Electronic Health \\
& using Proposed Electronic & Record (EHR) system to do what I want it to do \\
& EU3: The interaction with Proposed Electronic Health Record \\
& (EHR) system would be clear and understandable \\
& EU4: I would find Proposed Electronic Health Record (EHR) \\
& system to be flexible to interact with \\
& EU5: It would be easy for me to become skillful at using \\
& Proposed Electronic Health Record (EHR) system \\
\hline
\end{tabular}

Table 3: User satisfaction items

\begin{tabular}{lll}
\hline Construct & Operational definitions & Measured items \\
\hline User Satisfaction & User satisfaction refers to a level & US1: I completely satisfied in using the Proposed Electronic \\
& of satisfying that doctors and & Health Record (EHR) system \\
nurses of using Proposed Electronic & US2: I feel very confident in using the Proposed Electronic \\
Health Record (EHR) system & Health Record (EHR) system \\
& US3: I found it easy to share information about the patient \\
& condition, get feedback about the patient history using \\
& proposed Electronic Health Record (EHR) system \\
& US4: I can accomplish the task quickly using this procedure \\
& US5: I believe that from using Proposed Electronic Health \\
& Record (EHR) system will reduce errors and save time \\
\hline
\end{tabular}


Table 4: Attribute of usability items

\begin{tabular}{lll}
\hline Construct & Operational definitions & Measured items \\
\hline Attribute of usability & Attribute of usability shows up & AU1: It easy to interact with Proposed Electronic Health \\
& potential issues in the Proposed & Record (EHR) system \\
& Electronic Health Record (EHR) & AU2: The procedure through Proposed Electronic Health \\
system. The usability helps to & Record (EHR) system is clear \\
get feedback on what is or is & AU3: I found the various functions in this Proposed \\
not working and have a much & Electronic Health Record (EHR) were useful and meaningful \\
broader understanding of what & AU4: I found the various functions in the Proposed \\
doctors and nurse are doing and & Electronic Health Record (EHR) system were well integrated \\
& how they interact with the system & AU5: I think that I would like to use this Proposed \\
& Electronic Health Record (EHR) system always \\
\hline
\end{tabular}

Table 5: Top 3 highest items

\begin{tabular}{lll}
\hline ITEMS & MEAN & ST.DEV \\
\hline $\begin{array}{l}\text { Proposed Electronic Health Record (EHR) system will be improve } \\
\text { quality of care through greater access to information and history of the patient }\end{array}$ & 4.5 & 0.73 \\
$\begin{array}{l}\text { The interaction with Propose Electronic Health Record (EHR) system } \\
\text { would be clear and understandable }\end{array}$ & 4.1 & 0.92 \\
$\begin{array}{l}\text { I believe that from using proposed electronic health record system } \\
\text { will reduce errors and save time }\end{array}$ & 3.9 & 0.78 \\
\hline
\end{tabular}

Sampling Technique: Sampling is a procedure that entails utilizing a small number of units in a given population as a basis for drawing conclusions regarding the whole population (Jemain et al., 2007). The sample is considered as a subset of the population comprising of some members selected from it (Al-Omari and Jaber, 2008). We aim to be able to draw generalized conclusions based on the population under study.

Analysis Techniques: There are three objectives of implementing data analysis: (i) Getting overview for the sample data and its attributes, (ii) testing the goodness of data and (iii) validating the proposed hypotheses and system.

Variable Measurement: The methodology applied in the study is based on the questionnaire approach. The objective of the questionnaire approach is basically to evaluate the proposed electronic health record system. The questionnaire contains five sections: Personal information, perceived usefulness, perceived ease of use, user satisfaction and attribute of usability. All these sections have a number of questions constructed to evaluate the effectives of the proposed electronic health record system to the intended users.

\section{Results and Discussion}

To evaluate the performance of our Proposed Electronic Health Record (EHR) System, we conducted an experiment system, we asked 54 responders to use and discover the proposed electronic health record (EHR) system for several minutes and evaluate it. The respondents proved that the proposed electronic health record system will improve clinical documentation, quality, healthcare utilization tracking, billing and coding and make health records portable. Additionally, it is useful for rapid retrieval of information about the patients.
Therefore, based on the results of this evaluation, the proposed electronic health record system shows promise as a tool and a highly effective modality for tracking the patient condition more efficiently and easily and overcomes the damages, misplaced and loss of some papers relating to information of the patients by using our Proposed Electronic Health Record (EHR) system.

All the responders were belonging to the targeted group, the scope of this study. All variables were measured using 5- points Likert scale (Strongly Disagree, Disagree, Natural, Agree and Strongly Agree). From the study, the descriptive statistics for the highest items in Table 5. Item 1: Proposed Electronic Health Record (EHR) system will be improve quality of care through greater access to information and history of the patient, has the highest mean 4.5 with a standard deviation 0.73. The statistic of item 1 shown in Fig. 14. Then item 2: The interaction with Propose Electronic Health Record (EHR) system would be clear and understandable, has the second highest mean 4.1 with standard deviation 0.92 . The statistic of item 2 shown in Fig. 15. Finally, the item 3: I believe that from using proposed electronic health record system will reduce errors and save time, has the third highest mean 3.9 with standard deviation 0.78 . The statistic of item 3 shown in Fig. 16.

Information technology has influenced our lives to some extent anyhow, with its powerful characteristics that dramatically changed the way people act and interact with each other and their government in point of Electronic Health Records. After the evolution of Electronic Health Records in the world, the government looks to be the coming generation of the development. Developing strategies to run an Electronic Health Records system is becoming as one of the top aims for governments. 
Electronic Health Records is becoming very crucial action for changing the whole government agencies with use of new technologies.

Our world has been radically transformed by technology - smart phones, tablets and web-enabled devices have transformed our daily lives and the way we communicate. Medicine is an information-rich enterprise. A greater and more seamless flow of information within a digital health care infrastructure, created by Electronic Health Records (EHRs), encompasses and leverages digital progress and can transform the way care is delivered and compensated.
With EHRs, information is available whenever and wherever it is needed.

From the results of this survey for the main variables is revealed that: The proposed Electronic health records system make it possible for your health care providers to better manage your care through secure use and sharing of health information. It is built to share information with other health care providers, such as laboratories and specialists, therefore they contain information from all the clinicians involved in patient care.

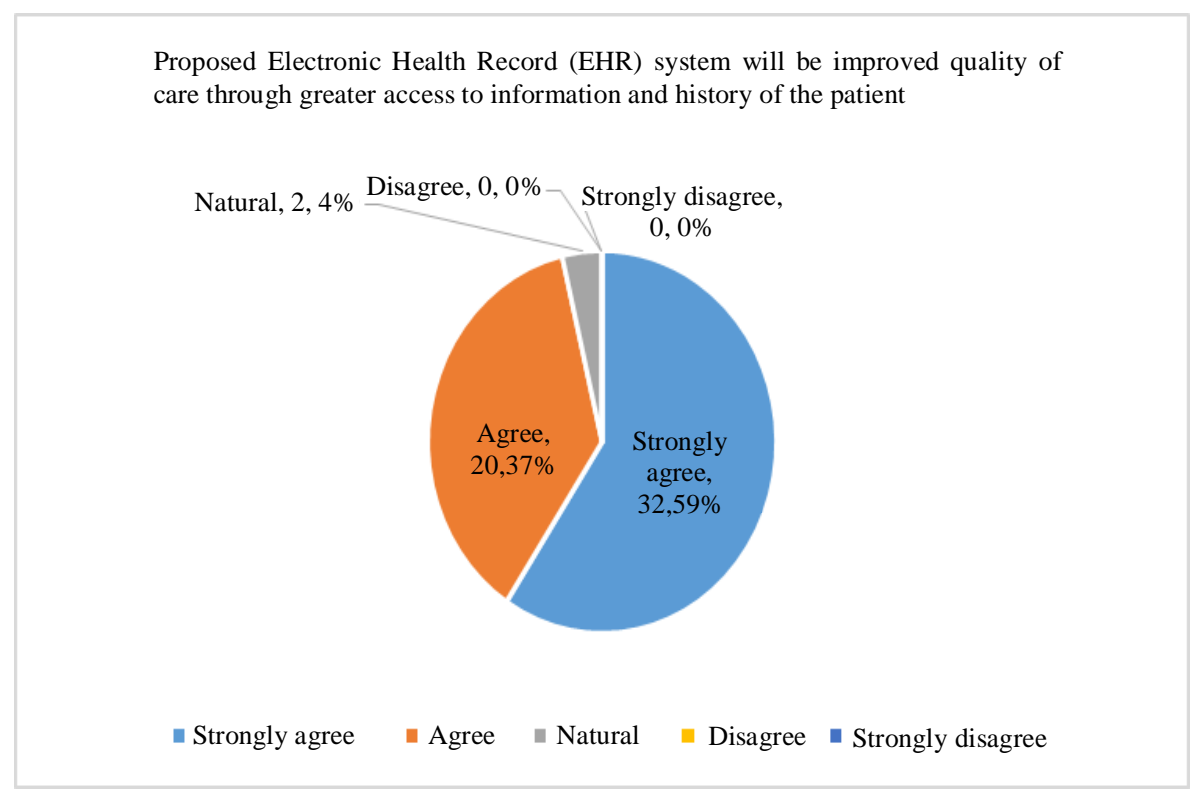

Fig. 14: Item 1 statistics (shows that 59\% of the respondents strongly agreed and 37\% are agreed of that the Proposed Electronic Health Record (EHR) system will be improved quality of care through greater access to information and history of the patient)

The interaction with proposed Electronic Health Record (EHR) system would be clear and understandable

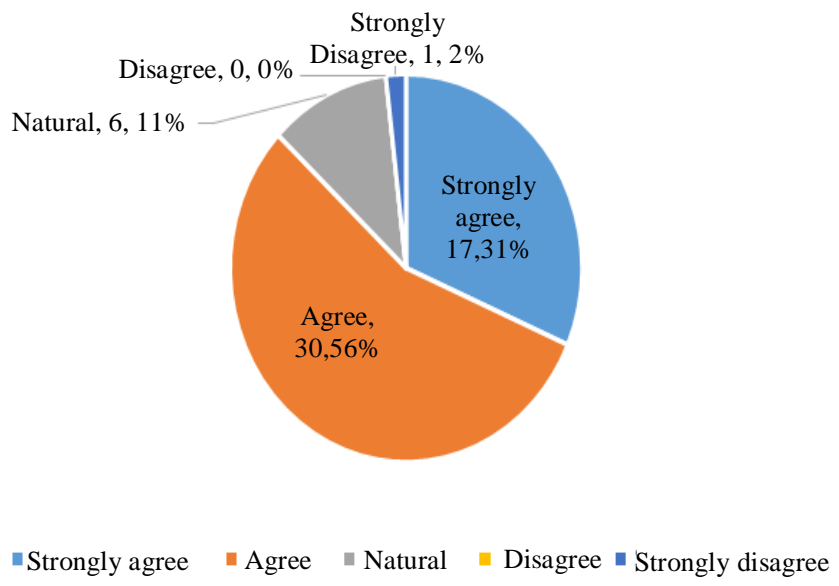

Fig. 15: Item 2 statistics (shows that 31\% of the respondents strongly agreed and 56\% are agreed of that the interaction with Proposed Electronic Health Record (EHR) system would be clear and understandable) 
I believe that from using proposed Electronic Health Record (EHR)

system will reduce errors and save time

Strongly

Disagree, $2,4 \%$ Disagree, $2,4 \%$

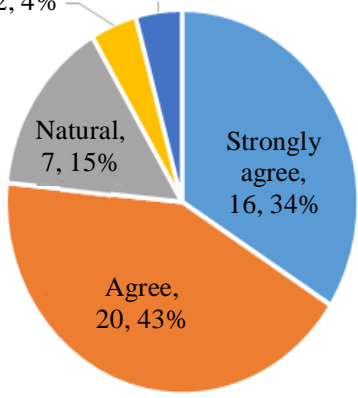

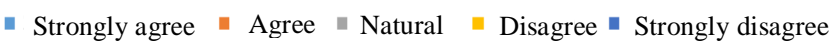

Fig. 16: Item 3 statistics (shows that $34 \%$ of the respondents strongly agreed and $43 \%$ are agreed of that the Proposed Electronic Health Record (EHR) system will reduce errors and save time

With electronic health records, your complete health care information can be accessed by your health care providers in a secure and timely manner. List of the functions of the Doctor by using the proposed health record system are:

- Update personal information

- View a list of patients

- View patient's records

- View or update diagnosis

- View and update treatment

- View or update chronic disease

- View or update laboratory

- View or update detection

- Contact with patient

- Write note to other doctors

With the help of the proposed electronic health records, the health care providers can have more accurate and complete information about the patient health such as: Medical history, Medications and test results to help ensure they can give you the best possible care.

Improved ability to share information about the patient with other providers for better coordinate the care they give to the patient. Improved Patient Care, Increase Patient Participation, Improved Care Coordination, Improved Diagnostics and Patient Outcomes, Practice Efficiencies and Cost Savings. It also, it also, this study aims to serve both patient and doctor concerning the patient's case and if his/her diagnosed disease will lead to future complications or not and include the recommended or the forbidden drugs together with the kind of foods he/she should only eat.

\section{Recommendations}

This project is just a model, not a supported version. It is allowed to be developed and added any necessary features by the Ministry of Health.

Some of the suggestions may be:

- Developing the website by choosing a supervisor or a manager to manage the responsibilities. The manger could be the Ministry of Health itself. The chosen manger will be able to add doctors and disable the feature of editing previous data

- Keeping this website as a page of the Ministry of Health site in order to make it official, stable and easy to access

- Designing an Arabic version of the system

- Verifying security and confidentiality of information and using some protection programs

- Adding a section in laboratory: Laboratory form of Serology and Immunology Chemistry

- Adding print command in order to make it easy for the doctor and the patient

- Adding some buttons such as: Nutrition, Adding Emergency Department and adding some subsections in examination section such as: Computerized Tomography Scan

\section{Conclusion}

Almost all governments in the world nowadays are implementing e-government for the purpose of costs reducing, services improving, time saving and increasing effectiveness and efficiency in all sectors of the government especially in electronic health record. That is why electronic health record became one of the primary target for Saudi government and all its agencies. 
In spite of the fact that enthusiasm for computerizing the health record is commonly high in both developed and developing countries tragically, now and again, the presentation of an EHR framework appears to be overpowering and practically distant to numerous social insurance suppliers and chairmen just as therapeutic record/wellbeing data directors. The obstacles may not be available technology but technical support and the cost of changing to an electronic system coupled with insufficient healthcare funding.

The healthcare sector remains at the edge of one of the greatest progressive changes in medicinal services practice in present day times. EHR advances remain to change medicinal services to improve things. In the event that EHR advancements are grasped and the best possible programming, equipment and IT framework are set up, the social insurance industry will remain to profit significantly. It will expand tolerant quality and patient wellbeing results. It can expand the human services office's primary concern and twist the cost bend of the rising national expense of social insurance.

Healthcare has been ease back to grasp EHR advances, the eventual fate of human services will stay to test at the same time, in the meantime, the upgrades in consideration and quality are energizing. The eventual fate of social insurance and the capacity of the people individuals to have the capacity to bear the cost of Healthcare, are relying upon the medicinal services industry to make EHR advances a fruitful endeavor.

\section{Acknowledgement}

We would like to thank College of Sciences and Arts at Unaizah, Qassim University, Kingdom of Saudi Arabia.

\section{Author's Contributions}

All authors are equally contributed in this work and this paper.

Hussain Mohammad Abu-Dalbouh: The author contributed to the review the various published articles in the field. Designed the study, developed the methodology, collected the data, performed the analysis, and writing of the manuscript and final approval.

Memonah Al-Matrouk: Invented the idea, designed the research plan and organized the study, helped shape the research, assisted in data analysis and interpretation, and provided critical feedback and comments on writing.

Norah Al-Zwaid: Helped shape the research, assisted in research design and methodology, and Contributed to the search and analysis system by used UML method.

Arwa Al-Handi: Helped shape the research, assisted in data collection and interpretation, and provided critical feedback and contributed to the search and questionnaire.

\section{Ethics}

This article is original and contains unpublished material. The corresponding author confirms that all of the other authors have read and approved the manuscript and no ethical issues involved.

\section{References}

Abu-Dalbouh, H., 2019. Developing mobile tracking applications for patient treatment. Comput. Inform. Sci., 12: 11-22. DOI: 10.5539/cis. v12n1p12

Abu-Dalbouh, H., M, Al-Buhairy and I, Al-Motiry, 2017. Applied the technology acceptance model in designing a questionnaire for mobile reminder system. Comput. Inform. Sci., 10: 15-24.

DOI: $10.5539 /$ cis.v10n2p15

Abu-Dalbouh, H., 2016a. An integrated expert user with end user in technology acceptance model for actual evaluation. Comput. Inform. Sci., 9: 47-53. DOI: $10.5539 /$ cis.v9n $1 \mathrm{p} 47$

Abu-Dalbouh, H., 2016b. Using a modified technology acceptance model to evaluate designing eight queens chess puzzle game. J. Comput. Sci., 12: 232-240. DOI: $10.3844 /$ jcssp.2016.232.240

Abu-Dalbouh, H., A. Al-Habeeb, A., Al-Kholifi, I., AlMotiry and M., Al-Buhairy, 2015. A mobile reminder system for elderly and Alzheimer's patients. Int. J. Comput. Sci., 12: 95-101.

Abu-Dalbouh, H., 2014a. A proposed mhealth model for improving the quality care in hospitals. Res. J. Applied Sci. Eng. Technol., 7: 1215-1219.

Abu-Dalbouh, H., 2014b. m-TOPP-UML: An extension to UML for the modeling of mobile tracking on patient progress system. Res. J. Applied Sci. Eng. Technol.,7: 1202-1208.

Abu-Dalbouh, H. and M.Z. Almueit, 2013. Designing mobile tracking solution in monitoring patients. Proceedings of the 6th International Conference on Information Technology, (CIT'13).

Abu-Dalbouh, H.M., 2013. A questionnaire approach based on the technology acceptance model for mobile tracking on patient progress applications. J. Comput. Sci., 9: 763-770.

DOI: $10.3844 /$ jcssp.2013.763.770

Al-Omari and A.I.K. Jaber, 2008. Modified ratio-type estimators of the mean using extreme ranked set sampling. J. Math. Stat., 4: 150-155.

DOI: $10.3844 /$ jmssp.2008.150.155

Cavoukian, A. and Peter G. Rossos, 2009. Personal Health Information: A Practical Tool for Physicians Transitioning from Paper-Based Records to Electronic Health Records. 
Chomeya, R., 2010. Quality of psychology test between likert scale 5 and 6 points. J. Soc. Sci., 6: 399-403. DOI: $10.3844 /$ jssp. 2010.399 .403

Creswell, J.W., 2011. Educational Research: Planning, Conducting and Evaluating Quantitative and Qualitative Research. 4th Edn., Pearson Education, Boston, ISBN-10: 0132613948, pp: 650.

Torrey, Â., 2011. Electronic health records and electronic medical records -- EHRs and EMRs. Patient Empowerment at About.com - Teaching Patients to Take Charge for their Health and Medical Care.

History of the Electronic Medical Record System. (n.d.). National assembly on school based health care.

Jemain, A.A., A. Al-Omari and K. Ibrahim, 2007. Multistage median ranked set sampling for estimating the population median. J. Math. Stat., 3: 58-64. DOI: $10.3844 /$ jmssp.2007.58.64
Kanaan, R.K., 2009. Making sense of e-government implementation in Jordan: A qualitative investigation. $\mathrm{PhD}$ Thesis, Center of Computing and Social Responsibility, De Montfort University, Leicester.

Lohr, S., 2009. How to make electronic medical records a reality. Unboxed - How to Make Electronic Medical Records a Reality.

Milliard, M., 2012. The 5-year plan where will healthcare be in 2017? Healthcare IT News, 9: 4-5.

Ministry of Health, 2014. http://www.moh.gov.sa/en/Ministry/About/Pages/de fault.aspx

Roman, L., 2009. Combined EMR, EHR and PHR manage data for better health. Drug Store News, 31: 40-78.

Wiedemann, L.A., 2012. A look at unintended consequences of EHR's. Health Manage. Technol., 33: $24-25$. 